\title{
Shigella Infections in Household Contacts of Pediatric Shigellosis Patients in Rural Bangladesh
}

\author{
Christine Marie George, Shahnawaz Ahmed, Kaisar A. Talukder, Ishrat J. Azmi, Jamie Perin, \\ R. Bradley Sack, David A Sack, O. Colin Stine, Lauren Oldja, Mohammad Shahnaij, \\ Subhra Chakraborty, Tahmina Parvin, Sazzadul Islam Bhuyian, Edward Bouwer, Xiaotong Zhang, \\ Trisheeta N. Hasan, Sharmin J. Luna, Fatema Akter, Abu S.G. Faruque
}

To examine rates of Shigella infections in household contacts of pediatric shigellosis patients, we followed contacts and controls prospectively for 1 week after the index patient obtained care. Household contacts of patients were 44 times more likely to develop a Shigella infection than were control contacts (odds ratio $44.7,95 \%$ Cl 5.5-361.6); 29 (94\%) household contacts of shigellosis patients were infected with the same species and serotype as the index patient's. Pulsed-field gel electrophoresis showed that $14(88 \%)$ of 16 with infected contacts had strains that were indistinguishable from or closely related to the index patient's strain. Latrine area fly counts were higher in patient households compared with control households, and 2 patient household water samples were positive for Shigella. We show high susceptibility of household contacts of shigellosis patients to Shigella infections and found environmental risk factors to be targeted in future interventions.

$\mathrm{I}^{\mathrm{n}}$ $n$ South Asia and Africa, an estimated 88.5 million diarrhea episodes are attributed to Shigella infections annually (1). Shigellosis occurs most often in children $<5$ years of age $(2,3)$. Two recent multicountry studies found that Bangladesh has the highest rates of shigellosis $(4,5)$. In the recent Global Enteric Multicenter Study (GEMS) conducted at a study site in Mirzapur, Bangladesh, Shigella was the third leading cause of moderate-to-severe diarrhea in children 12-23 months of age and the second leading cause of moderate-to-severe diarrhea in children 24-59 months of age (5). In addition, hospital-based surveillance of Shigella in Bangladesh found that patients from rural health facilities have higher rates of Shigella isolates than patients from

Author affiliations: Johns Hopkins University, Baltimore, Maryland, USA (C.M. George, J. Perin, R.B. Sack, D.A. Sack, L. Oldja,

S. Chakraborty, E. Bouwer, X. Zhang); icddb,b, Bangladesh (S. Ahmed, K.A. Talukder, I.J. Azmi, M. Shahnaij, T. Parvin, S.I. Bhuyian, T.N. Hasan, S.J. Luna, F. Akter, A.S.G. Faruque); University of Maryland School of Medicine, Baltimore (O.C. Stine)

DOI: http://dx.doi.org/10.3201/eid2111.150333 urban facilities (e.g., 3\% in urban Dhaka vs. 12\% in rural Mirzapur during 2011) (6). Previous studies have identified risk factors for developing shigellosis, such as age (7-9), high fly counts $(10-12)$, contaminated food $(13,14)$, and recent overnight travel (8). Furthermore, a recent study in rural Bangladesh found that $10 \%$ of tube wells sampled had detectable Shigella (15).

Household studies have indicated that family members of shigellosis patients are at much higher risk for developing a Shigella infection than the general population (13-19 cases/100 shigellosis patient households vs. 7 cases/100 control households) $(7,8)$. However, little research has been done to identify clinical and environmental transmission routes for Shigella infection in this susceptible population.

Shigella includes 4 species and numerous serotypes: $S$. flexneri (17 serotypes), $S$. dysenteriae (16 serotypes), $S$. boydii (20 serotypes), and $S$. sonnei (1 serotype) (16). A study in Wisconsin found that isolates from family members of index shigellosis patients were always the same serotype as the index patient's (7). In contrast, studies in rural (8) and urban (9) Bangladesh found that $75 \%$ and $72 \%$, respectively, of infected household contacts of shigellosis patients excreted serotypes different from the index patient's serotype. These studies suggest that Shigella infections in Bangladesh are attributable to both secondary transmission and external infecting sources. To examine the rate of Shigella infection within households of shigellosis patients and to investigate risk factors for infection, we prospectively observed a cohort of household contacts of pediatric shigellosis patients and community controls in rural Mirzapur, Bangladesh.

\section{Methods}

This study was conducted in Mirzapur, a subdistrict of Bangladesh's Tangail district, at a field site of the icddr,b. Mirzapur is the Bangladesh site of the GEMS Demographic Surveillance System. We received ethical approval for this study from the icddr,b ethical review committee and an exemption from the Institutional Review Board at 
Household Contacts of Shigellosis Patients

Table 1. Characteristics of household contacts of pediatric shigellosis patients and of community controls, rural Bangladesh

\begin{tabular}{|c|c|c|c|}
\hline \multirow[b]{2}{*}{ Characteristic } & \multicolumn{2}{|c|}{ Median \pm SD (range) or no. (\%) } & \multirow[b]{2}{*}{$\mathrm{p}$ value } \\
\hline & Patient contacts, $\mathrm{n}=81$ & Control contacts, $\mathrm{n}=77$ & \\
\hline No. enrolled contacts per household* & $3.0 \pm 0.73(2.0-5.0)$ & $3.0 \pm 0.95(2.0-6.0)$ & 0.25 \\
\hline No. persons living in the household for past $6 \mathrm{mo}^{*}$ & $5.0 \pm 1.4(3.0-9.0)$ & $6.0 \pm 2.7(3.0-15.0)$ & 0.16 \\
\hline Age of contacts, y† & $27.0 \pm 16.9(1.8-72.0)$ & $30.0 \pm 18.6(3.5-89.0)$ & 0.47 \\
\hline $\begin{array}{l}\text { Hours contacts spent outside their home in the past } 48 \mathrm{~h} \text { during } \\
\text { surveillance period } \dagger\end{array}$ & $2.0 \pm 1.8(0-6.3)$ & $1.0 \pm 1.8(0-7.3)$ & 0.09 \\
\hline Female sex $\ddagger$ & $48(58)$ & $46(61)$ & 0.75 \\
\hline Drank water outside their home during surveillance period $\ddagger$ & $57(69)$ & $48(62)$ & 0.41 \\
\hline Consumed food outside their home during surveillance period $\ddagger$ & $51(61)$ & $36(47)$ & 0.08 \\
\hline Consumed uncooked vegetables or fruits during surveillance period $\ddagger$ & $22(27)$ & $12(16)$ & 0.12 \\
\hline $\begin{array}{l}\text { *For household characteristics, a Wilcoxon signed-rank test was used for paired } \\
\text { †For individual characteristics, a Wilcoxon rank-sum test was used for continuo } \\
\text { †For individual characteristics, a Fisher exact test was used for categorical varia }\end{array}$ & $\begin{array}{l}\text { ontinuous variables. } \\
\text { variables. } \\
\text { es. }\end{array}$ & & \\
\hline
\end{tabular}

the Johns Hopkins Bloomberg School of Public Health (Baltimore, MD, USA). Written informed consent was obtained from all study participants or their guardians.

A cohort of household contacts of index shigellosis patients and matched community controls was followed prospectively for 7 days after each index patient visited the Kumudini Women's Medical College and Hospital in Mirzapur for health care. Our sample size was determined by the number of pediatric shigellosis patients that could be recruited during October 2013-July 2014. Patients with suspected pediatric shigellosis were identified as children $<5$ years of age with dysentery, which was defined as having $\geq 1$ stool containing blood during the previous 24 hours, as reported by a guardian or observed by research personnel. Community controls were matched to index shigellosis patients on the basis of age (within 3 months) and village location and were randomly selected by using the GEMS Demographic Surveillance System. Stool samples were collected from patients with suspected shigellosis and from community controls at time of enrollment in the study and were immediately sent in a cooler to the icddr,b Enteric and Food Microbiology Laboratory in Dhaka, Bangladesh, for bacterial culture analysis to detect Shigella.

Households of suspected shigellosis patients whose samples were found to be negative for Shigella by culture were excluded from the study. All index patients enrolled in the study received ciprofloxacin as part of their standard course of care at Kumudini Hospital.

After enrollment of pediatric shigellosis patients, we recruited household contacts of shigellosis patients and of community controls. Household contacts were defined as persons sharing the same cooking pot as the index shigellosis patient or control during the previous 3 days. To be eligible for the study, household contacts had to report that they would be present in the household of the patient or control for the next 7 days and be present for most household visits. Household contacts were followed prospectively for clinical and environmental surveillance by conducting household visits at days 1, 3, 5, and 7 after the initial visit of the index shigellosis patient at Kumudini Hospital.
For clinical surveillance, household contacts were asked to report whether, during the previous 48 hours, they had diarrhea ( $\geq 3$ loose stools during a 24 -hour period), dysentery (blood in stool observed by caregiver or research personnel), or vomiting. A stool sample was collected from enrolled household contacts at every visit. In addition, at each household visit, a questionnaire was administered to enrolled contacts to collect information on previously identified risk factors for Shigella infection. For environmental surveillance, on days 1 and 5, a water sample was collected directly from the household's primary drinking water source, and a second sample was collected from drinking water stored in the home for immediate consumption. The water samples were tested for Shigella spp. by bacterial culture and PCR. Trained field assistants also conducted fly counts by using a Scudder grill at all surveillance visits over a period of 30 minutes at the kitchen and latrine area of each household, according to previously published methods (12). Weekly fly counts for each household were the total number of flies observed during surveillance visits.

All stool and water samples collected were analyzed at the icddr,b Enteric and Food Microbiology Laboratory in Dhaka. The laboratory received no information identifying whether samples were from patient or control households. For isolation of Shigella, stool and water samples were cultured on MacConkey and Shigella-Salmonella agar media, and Shigella was isolated and serotyped by using standard microbiologic and biochemical methods described previously (4). In brief, water samples of $1,000 \mathrm{~mL}$ were filtered through $0.22 \mu \mathrm{m}$ pore-size filters. The filter paper was enriched in $25 \mathrm{~mL}$ gram-negative broth at $37^{\circ} \mathrm{C}$ overnight and then analyzed by culture. Template DNA was prepared from the enriched broth and tested for the ipaH gene, according to previously published methods (16).

To determine genetic relatedness of Shigella strains isolated within households, pulsed-field gel electrophoresis (PFGE) was performed on all Shigella-positive water and stool samples, according to the PulseNet protocol (17). Agarose-embedded genomic DNA of Shigella strains was digested by using $X b a \mathrm{I}$, and fragments were separated by 
Table 2. Demographic and environmental characteristics of households of pediatric shigellosis patients and of community controls, rural Bangladesh

No. $(\%)$ or median \pm SD (range)

\begin{tabular}{|c|c|c|c|}
\hline Characteristic & $\begin{array}{l}\text { Patient households, } \\
n=27\end{array}$ & $\begin{array}{l}\text { Control households, } \\
n=27\end{array}$ & $\mathrm{p}$ value \\
\hline \multicolumn{4}{|l|}{ Demographic $^{*}$} \\
\hline \multicolumn{4}{|l|}{ Age of child, patient or control† } \\
\hline $0-11 \mathrm{mo}$ & $3(11)$ & $3(11)$ & 1.00 \\
\hline $12-23 \mathrm{mo}$ & $11(41)$ & $11(41)$ & \\
\hline $24-35 \mathrm{mo}$ & $6(22)$ & $6(22)$ & \\
\hline $36-47 \mathrm{mo}$ & $6(22)$ & $6(22)$ & \\
\hline $48-59 \mathrm{mo}$ & $1(4)$ & $1(4)^{\prime}$ & \\
\hline Female sex, patient or control† & $13(48)$ & $13(48)$ & \\
\hline \multicolumn{4}{|l|}{ Primary caregiver educational levelł } \\
\hline No formal education & $2(7)$ & $4(15)$ & 0.48 \\
\hline Less than primary school & $2(7)$ & $3(11)$ & \\
\hline Completed primary school or greater & $23(86)$ & $20(74)$ & \\
\hline Electricity in home ${ }^{*}$ & $20(74)$ & $19(70)$ & 0.75 \\
\hline \multicolumn{4}{|l|}{ Environmental } \\
\hline \multicolumn{4}{|l|}{ Main source of drinking water* } \\
\hline Shallow tube well & $16(59)$ & $16(59)$ & 1.00 \\
\hline Deep tube well & $11(41)$ & $11(41)$ & \\
\hline Households with water source Shigella positive by PCR for ipaH gene* & 0 & $2(7)$ & 0.48 \\
\hline Households with stored water Shigella positive by culture* & $2(7)$ & 0 & 0.48 \\
\hline Households with stored water Shigella positive by PCR* & $2(7)$ & $1(4)$ & 1.00 \\
\hline Households with no soap observed at any surveillance visit*§ & $18(67)$ & $19(70)$ & 0.75 \\
\hline \multicolumn{4}{|l|}{ Floor type* } \\
\hline Earth & $18(67)$ & $23(85)$ & 0.13 \\
\hline Concrete & $9(33)$ & $4(15)$ & \\
\hline \multicolumn{4}{|l|}{ Latrine type $\neq$} \\
\hline Ventilated improved pit latrine & $14(52)$ & $12(44)$ & 0.49 \\
\hline Pour flush toilet & $6(22)$ & $6(22)$ & \\
\hline Traditional pit latrine & $6(22)$ & $8(30)$ & \\
\hline No facility & $1(4)$ & $1(4)$ & \\
\hline Latrine area weekly fly counts $\pi$ & $27 \pm 20(0-84)$ & $16 \pm 13(0-48)$ & 0.0014 \\
\hline Kitchen area weekly fly counts & $59 \pm 55(0-216)$ & $44 \pm 48(0-192)$ & 0.47 \\
\hline \multicolumn{4}{|l|}{$\begin{array}{l}\text { *McNemar test was used for paired categorical variables. } \\
\text { †All patient-control pairs were the same. } \\
\text { †Friedman test was used for paired categorical variables with }>2 \text { levels. } \\
\text { §Soap within } 10 \text { steps of location reported to be used for household defecation. } \\
\text { TWilcoxon signed-rank test was used for paired continuous variables. }\end{array}$} \\
\hline
\end{tabular}

using a CHEF-DR II apparatus (Bio-Rad, Hercules, CA, USA) (18). Genetic relatedness was determined on the basis of previously published methods (19). To compare strains within a single household, 4 categories of genetic relatedness were used: a) "indistinguishable" (all fragments matched); b) "closely related" (1-3 fragments differed); c) "possibly related" (4-6 fragments differed); and d) "unrelated" ( $\geq 7$ fragments differed).
A Shigella-infected person was defined as a person with a stool sample positive for Shigella spp. by culture. Various tests were used for household-level variables: a McNemar test for paired binary variables; a Friedman test for clustered categorical variables with $>2$ levels; and a Wilcoxon signed-rank test for paired continuous variables (Tables 1, 2). For individual-level variables, a Fisher exact test was used for categorical variables

Table 3. Household infection characteristics of pediatric shigellosis patients and of community controls, rural Bangladesh*

\begin{tabular}{|c|c|c|c|}
\hline Characteristic & $\begin{array}{l}\text { Patient households, } \\
\text { no. }(\%), n=27\end{array}$ & $\begin{array}{l}\text { Control households, } \\
\text { no. }(\%), n=27\end{array}$ & $\mathrm{p}$ value \\
\hline Households with $\geq 1$ infected contact & $16(59)$ & $1(4)$ & $<0.0001$ \\
\hline Households with $\geq 1$ contact with infection at visit 1 & $9(33)$ & $1(4)$ & 0.02 \\
\hline $\begin{array}{l}\text { Households with } \geq 1 \text { contact with initial infection detected at visits other than } \\
\text { visit } 1\end{array}$ & $11(41)$ & 0 & 0.001 \\
\hline Households with >1 infected symptomatic contact $\ddagger$ & $4(15)$ & 0 & 0.07 \\
\hline $\begin{array}{l}\text { Households with } \geq 1 \text { infected contact with same species and serotype as index } \\
\text { patient's }\end{array}$ & $15(94)$ & - & - \\
\hline $\begin{array}{l}\text { Households with } \geq 1 \text { contact with different species and serotype than index } \\
\text { patient's }\end{array}$ & $2(12)$ & - & - \\
\hline
\end{tabular}


Household Contacts of Shigellosis Patients

Table 4. Characteristics of household contacts with Shigella infections for pediatric shigellosis patients and community controls, rural Bangladesh

\begin{tabular}{|c|c|c|c|c|c|}
\hline \multirow[b]{2}{*}{ Characteristic } & \multicolumn{2}{|c|}{ Patient contacts } & \multicolumn{2}{|c|}{ Control contacts } & \multirow[b]{2}{*}{$p$ value* } \\
\hline & No. $(\%)$ & Total no. & No. (\%) & Total no. & \\
\hline Contacts infected & $31(37)$ & 83 & $1(1)$ & 77 & $<0.0001$ \\
\hline Contacts with symptomatic infections $\dagger$ & $6(7)$ & 83 & 0 & 77 & 0.03 \\
\hline Contacts with infection detected on visit 1 of surveillance & $13(16)$ & 83 & $1(1)$ & 77 & 0.0013 \\
\hline $\begin{array}{l}\text { Contacts with initial infection detected on visits other than visit } 1 \text { of } \\
\text { surveillance }\end{array}$ & $18(22)$ & 83 & 0 & 77 & \\
\hline \multicolumn{6}{|l|}{ Infected contacts by sex } \\
\hline M & $18(51)$ & 35 & 0 & 31 & 0.44 \\
\hline $\mathrm{F}$ & $13(27)$ & 48 & $1(2)$ & 46 & \\
\hline \multicolumn{6}{|l|}{ Infected contacts by relation to patient or control child } \\
\hline Mother & $9(35)$ & 26 & 0 & 26 & 0.09 \\
\hline Father & $8(53)$ & 15 & 0 & 16 & \\
\hline Brother & $6(55$ & 11 & 0 & 12 & \\
\hline Sister & $2(17)$ & 12 & $1(10)$ & 10 & \\
\hline Other relative & $6(32)$ & 19 & 0 & 13 & \\
\hline \multicolumn{6}{|l|}{ Infected contacts by Shigella species and serotype } \\
\hline S. flexneri & $20(65)$ & 31 & 0 & 1 & 0.63 \\
\hline S. flexneri $1 \mathrm{~b}$ & $2(6)$ & 31 & 0 & 1 & \\
\hline S. flexneri 1c & $3(10)$ & 31 & 0 & 1 & \\
\hline S. flexneri 2a & $12(39)$ & 31 & 0 & 1 & \\
\hline S. flexneri 3a & $3(10)$ & 31 & 0 & 1 & \\
\hline S. flexneri $4 \mathrm{X}$ & 0 & 31 & 0 & 1 & \\
\hline S. sonnei & $9(29)$ & 31 & $1(100)$ & 1 & \\
\hline S. boydii & $2(6)$ & 31 & 0 & 0 & \\
\hline S. boydii 7 & $1(3)$ & 31 & 0 & 0 & \\
\hline S. boydii & $1(3)$ & 31 & 0 & 0 & \\
\hline S. dysenteriae & 0 & 31 & 0 & 0 & \\
\hline
\end{tabular}

and a Wilcoxon rank-sum test for continuous variables (Tables 1, 2).

Logistic regression was used to estimate the odds of developing a Shigella infection. Generalized estimating equations were used to account for clustering within households and in patient-control pairs and to estimate an odds ratio (OR) and approximate 95\% CIs. Clusters in this analysis are the 27 patient-control pairs. A bivariate analysis was performed in which index patient or control child status in the household was used as the single predictor, and a binary outcome was used to determine whether household members developed a Shigella infection. All analyses were performed by using SAS, version 9.3 (SAS Institute, Inc., Cary, NC, USA).

\section{Results}

During October 2013-July 2014, a total of 27 shigellosis patients with 83 household contacts and 27 community controls with 77 household contacts were followed prospectively. Of the initial 61 suspected shigellosis patients who were screened, 29 were excluded because cultures were negative for Shigella, and 5 were excluded because the caregiver was too busy or uninterested in the study. Of the 33 community controls screened, 6 were excluded because they did not pass stool on visit 1 . Of 88 shigellosis-patient household contacts and 81 control household contacts who were screened for eligibility, 5
$(6 \%)$ and $4(5 \%)$, respectively, were excluded from the study because they did not pass stool on visit 1 .

Median age for household contacts was 27 years for patient households and 30 years for control households (Table 1). Of the 83 household contacts in patient households, $48(58 \%)$ were women, compared with $47(61 \%)$ of the 77 contacts in control households. Patient and control households did not differ significantly by age, sex, number enrolled, or number of total contacts (Table 1). Among household contacts of patients and control children, 52 (33\%) were mothers, 31 (19\%) fathers, 23 (14\%) brothers, $22(14 \%)$ sisters, and $32(20 \%)$ other relatives. Contact relationship to the patient or control child did not differ significantly $(\mathrm{p}=0.88)$.

During the surveillance period, patient contacts reported spending more time outside the home than did control contacts (median time outside home during previous 48 hours, 2 hours vs. 1 hour; $p=0.09$ ); eating more food outside the home $(61 \%$ vs. $47 \% ; \mathrm{p}=0.08)$; and consuming more uncooked vegetables and fruits $(27 \%$ vs. $16 \%$; $p$ $=0.12$ ). These differences were not statistically significant (Table 1). The rate for acquiring stool samples was $97 \%$ for enrolled household contacts and did not differ significantly for patient and control households $(\mathrm{p}=0.15)$.

We found no significant differences between patient and control households in caregiver's education level, type of latrine or floors, or presence of soap at the 
Table 5. Patient households with Shigella-infected household contacts by Shigella species and serotype and visit number at which infection was detected, rural Bangladesh*

\begin{tabular}{|c|c|c|c|c|c|}
\hline Household & $\begin{array}{l}\text { Household } \\
\text { member }\end{array}$ & Species and serotype & Visit no. & $\begin{array}{l}\text { No. PFGE genotypes } \\
\text { within household }\end{array}$ & $\begin{array}{l}\text { Household genetic } \\
\text { relatedness of strains } \dagger\end{array}$ \\
\hline \multirow[t]{4}{*}{ Household 1} & Patient & S. flexneri $2 a$ & 1 & 2 & Closely related \\
\hline & Contact 1 & S. flexneri $2 a$ & 3 & & \\
\hline & Contact 2 & S. flexneri $2 a$ & 1 & & \\
\hline & Contact 2 & S. flexneri $2 a$ & 2 & & \\
\hline \multirow[t]{4}{*}{ Household 2} & Patient & S. flexneri $2 \mathrm{a}$ & 1 & 2 & Unrelated \\
\hline & Contact 1 & S. flexneri $2 \mathrm{a}$ & 3 & & \\
\hline & Contact 1 & S. flexneri $2 \mathrm{a}$ & 4 & & \\
\hline & Contact 2 & S. boydii & 1 & & \\
\hline \multirow[t]{5}{*}{ Household 3} & Patient & S. sonnei & 1 & 1 & Indistinguishable \\
\hline & Contact 1 & S. sonnei & 1 & & \\
\hline & Contact 1 & S. sonnei & 2 & & \\
\hline & Contact 2 & S. sonnei & 4 & & \\
\hline & Stored water & S. sonnei & 1 & & \\
\hline \multirow[t]{3}{*}{ Household 4} & Patient & S. sonnei & 1 & 1 & Indistinguishable \\
\hline & Contact 1 & S. sonnei & 1 & & \\
\hline & Contact 1 & S. sonnei & 2 & & \\
\hline \multirow[t]{5}{*}{ Household 5} & Patient & S. flexneri $2 a$ & 1 & 2 & Closely related \\
\hline & Contact 1 & S. flexneri $2 \mathrm{a}$ & 4 & & \\
\hline & Contact 2 & S. flexneri $2 \mathrm{a}$ & 2 & & \\
\hline & Contact 2 & S. flexneri $2 a$ & 3 & & \\
\hline & Contact 2 & S. flexneri $2 a$ & 4 & & \\
\hline \multirow[t]{6}{*}{ Household 6} & Patient & S. flexneri $2 a$ & 1 & 2 & Closely related \\
\hline & Contact 1 & S. flexneri $2 \mathrm{a}$ & 1 & & \\
\hline & Contact 1 & S. flexneri $2 \mathrm{a}$ & 2 & & \\
\hline & Contact 2 & S. flexneri $2 a$ & 1 & & \\
\hline & Contact 2 & S. flexneri $2 a$ & 2 & & \\
\hline & Contact 3 & S. flexneri $2 a$ & 1 & & \\
\hline \multirow[t]{5}{*}{ Household 7} & Patient & S. flexneri 1c & 1 & 3 & Closely related \\
\hline & Contact 1 & S. flexneri 1c & 4 & & \\
\hline & Contact 2 & S. flexneri 1c & 3 & & \\
\hline & Contact 3 & S. flexneri 1c & 2 & & \\
\hline & Contact 3 & S. flexneri 1c & 4 & & \\
\hline \multirow[t]{2}{*}{ Household 8} & Patient & S. flexneri $4 \mathrm{X}$ & 1 & 2 & Unrelated \\
\hline & Contact 1 & S. boydii 7 & 2 & & \\
\hline \multirow[t]{4}{*}{ Household 9} & Patient & S. sonnei & 1 & 1 & Indistinguishable \\
\hline & Contact 1 & S. sonnei & 1 & & \\
\hline & Contact 1 & S. sonnei & 2 & & \\
\hline & Contact 2 & S. sonnei & 2 & & \\
\hline \multirow[t]{5}{*}{ Household 10} & Patient & S. flexneri 1b & $\frac{2}{1}$ & 3 & Closely related \\
\hline & Contact 1 & S. flexneri $1 \mathrm{~b}$ & 1 & & \\
\hline & Contact 1 & S. flexneri $1 \mathrm{~b}$ & 2 & & \\
\hline & Contact 1 & S. flexneri $1 \mathrm{~b}$ & 3 & & \\
\hline & Contact 2 & S. flexneri $1 \mathrm{~b}$ & 1 & & \\
\hline \multirow[t]{4}{*}{ Household 11} & Patient & S. flexneri $2 a$ & 1 & 1 & Indistinguishable \\
\hline & Contact 1 & S. flexneri $2 \mathrm{a}$ & 3 & & \\
\hline & Contact 1 & S. flexneri $2 \mathrm{a}$ & 4 & & \\
\hline & Contact 2 & S. flexneri $2 \mathrm{a}$ & 3 & & \\
\hline \multirow[t]{4}{*}{ Household 12} & Patient & S. flexneri 3a & 1 & 1 & Indistinguishable \\
\hline & Contact 1 & S. flexneri 3a & 4 & & \\
\hline & Contact 2 & S. flexneri 3a & 4 & & \\
\hline & Contact 3 & S. flexneri 3a & 2 & & \\
\hline \multirow[t]{3}{*}{ Household 13} & Patient & S. sonnei & 1 & 2 & Closely related \\
\hline & Contact 1 & S. sonnei & 2 & & \\
\hline & Contact 1 & S. sonnei & 3 & & \\
\hline \multirow[t]{3}{*}{ Household 14} & Patient & S. sonnei & 1 & 1 & Indistinguishable \\
\hline & Contact 1 & S. sonnei & 1 & & \\
\hline & Contact 1 & S. sonnei & 2 & & \\
\hline Household 15 & Patient & S. flexneri $2 \mathrm{a}$ & 1 & 2 & Closely related \\
\hline & Contact 1 & S. flexneri $2 \mathrm{a}$ & 1 & & \\
\hline & Contact 2 & S. flexneri $2 a$ & 1 & & \\
\hline Household 16 & Patient & S. sonnei & 1 & 1 & Indistinguishable \\
\hline & Contact 1 & S. sonnei & 4 & & \\
\hline & Contact 2 & S. sonnei & 4 & & \\
\hline
\end{tabular}


household latrine area, a proxy measure for handwashing with soap (Table 2). All households relied on tube wells as their primary drinking water source. The latrine areas of patient households had significantly higher weekly fly counts compared with those of control households $(\mathrm{p}=$ 0.001 ), but weekly kitchen fly counts did not differ significantly $(\mathrm{p}=0.47)$. In patient households, $33 \%$ had concrete floors compared with $15 \%$ of control households; this difference was not statistically significant $(\mathrm{p}=0.13)$. Household water samples from $2(7 \%)$ patient households were positive by PCR for the ipaH gene of Shigella and were culture positive for non-type $1 S$. dysenterae and $S$. sonnei during the surveillance period, compared with 1 PCRpositive (for the $i p a H$ gene) household water sample and 2 PCR-positive samples from household water sources in control households.

Of the 27 patient households, 16 (59\%) had $\geq 1$ Shigella-infected contact during the 7-day surveillance period, compared with 1 (4\%) control household, in which an asymptomatic Shigella infection was detected on day 1 of clinical surveillance (Table 3 ). In a bivariate model that used patient household as the predictor, the odds of developing a Shigella infection were 44 times higher for patient contacts than for control contacts (OR 44.7, 95\% CI 5.5-361.6). The 16 patient households had 31 Shigella-infected contacts, compared with 1 Shigella-infected contact in 1 control household (Table 4). Four (15\%) patient households had 6 contacts with symptomatic Shigella infection (i.e., having diarrhea, vomiting, or blood in stool during the previous 48 hours). Shigella infections for 13 (42\%) of 31 Shigella-infected patient contacts (asymptomatic and symptomatic) were first detected on day 1 of clinical surveillance; $6(19 \%)$ were detected on day $3,5(16 \%)$ on day 5 , and $7(23 \%)$ on day 7 .

In patient households, a Shigella infection developed in $18(51 \%)$ of 35 male contacts and in $13(27 \%)$ of 48 female contacts during the surveillance period $(\mathrm{p}=0.02)$. Five of the 6 symptomatic Shigella infections were in men, and 4 of the infections were first detected on day 1 or 3 of surveillance. Difference in day of initial detection by sex was not significant $(p=0.53)$, but male contacts spent significantly more time outside their homes during the surveillance period $(p<0.0001)$ and reported drinking significantly more water outside their homes $(p<0.0001)$ than did female contacts.

During the surveillance period, 4 patient contacts reported using antibacterial drugs; 3 of those had a symptomatic Shigella infection, 1 of whom was hospitalized for symptoms. This person tested positive on visit 1 . To estimate duration of shedding for patient household contacts, we observed the time during which shedding occurred for 6 household contacts with a Shigella infection first detected on visit 2 . Of these 6 contacts, $5(83 \%)$ had detectable shedding for $\leq 2$ days: 3 for 1 day, 2 for 2 days, and 1 for 3 days.
Among the 31 patient household contacts in whom Shigella infection developed, 29 (94\%) were infected with the same species and serotype as the index patient in their household (Table 5). Twenty (65\%) of the 31 patient household contacts with detectable Shigella in stool by culture had S. flexneri (2 S. flexneri 1b, 3 S. flexneri 1c, $12 S$. flexneri 2a, and 3 S.flexneri 3a); 9 (29\%) had S. sonnei; and $2(6 \%)$ had S. bodyii (1 S. boydii 7 and 1 S. boydii of an unknown serotype) (16-18). In the 16 patient households with infected household contacts, 7 (44\%) contacts had strains indistinguishable from those of the index patient by PFGE analysis; 7 (44\%) had closely related strains; and 2 (12\%) had unrelated strains (Table 5).

\section{Discussion}

We found that the odds of developing a Shigella infection were $>44$ times higher for contacts of pediatric shigellosis patients than for control contacts (OR 44.7, 95\% CI 5.5361.6). We also observed that $94 \%$ of patient household contacts had the same species and serotype as the index patient. Consistent with this finding, PFGE analysis found that $88 \%$ of households with infected household contacts had strains that were indistinguishable from or closely related to the index patient's strain. In contrast, 2 previous studies in Bangladesh found that only one quarter of household contacts had the same species and serotype as the index patient in their home $(8,9)$. Our finding suggests that a single infectious pathogen is being spread in study households; however, whether the infections are caused by a shared environmental source or secondary transmission from an infected household member is unclear.

We observed that most (59\%) patient households had $\geq 1$ household contact with a Shigella infection over the 7 -day surveillance period, and $25 \%$ of these households had contacts who had symptomatic infections. In comparison, $1(4 \%)$ control household contact had a Shigella infection, which was asymptomatic. The proportion of shigellosis patient households with Shigella-infected contacts in our study is higher than has been previously reported. In a study in Peru, 34\% of households of index shigellosis patients during the 1-week surveillance period had infected contacts (20). Another study conducted in rural Bangladesh in 1974 found that $19 \%$ of members of household compounds (i.e., multiple households living together) developed Shigella infection over a 10-day period after identification of the index shigellosis patient, compared with $7 \%$ of members of control household compounds (21). The reason our study found a higher rate of infection in household contacts of shigellosis patients is unknown but may reflect differences in environmental risk factors or population immunity.

Despite no significant difference in toilet type, we found significantly higher fly counts in the latrine areas of patient households than in control households during the 
surveillance period (Table 2). This finding likely suggests that patient households had latrines with poorer sanitary conditions than did control households. Similarly, a recent study conducted in the same site found a significant association between seasonal fly densities and peaks in pediatric shigellosis patients (12). Furthermore, these significant associations are consistent with the growing body of literature that implicates houseflies as vectors of shigellosis. The 2 flies thought to be responsible for transmission of Shigella are Musca domestica, because of its mobility, and M. sorbens, because it commonly breeds in human feces. Previous studies in Bangladesh, Myanmar, Egypt, and the United States have detected Shigella in flies by culture (11). An intervention study conducted on 2 military field bases in Israel found that baited fly traps reduced fly counts by $64 \%$ and rates of shigellosis by $85 \%$ compared with fly counts and shigellosis rates on the control base (10). These studies suggest that fly control could be a promising intervention to reduce Shigella transmission in the study population. Future studies should more closely evaluate the potential of flies to be a vector of Shigella in our study population by culturing flies and conducting fly species identification.

Our study also found 2 (7\%) patient households with stored water samples positive for Shigella. In 1 household, detectable $S$. sonnei by culture was found in stool from the patient and 2 household contacts and in stored water. This finding suggests potential secondary contamination of stored water by a household member, particularly because none of the corresponding source water samples had detectable Shigella by culture. In another household, $S$. dysenteriae was found in stored water but was not detected in any household members. A potential explanation for this finding is that the Shigella came from the household tube well. A previous study in rural Bangladesh identified Shigella by PCR in $10 \%$ of tube wells; that study also found that $40 \%$ of these tube wells were contaminated with rotavirus, $10 \%$ with Vibrio spp., and $8 \%$ with pathogenic Escherichia coli (15). The mostly likely source of Shigella in tube well water is fecal contamination from latrines, which are commonly located near tube wells used for drinking in rural Bangladesh. Further research is needed to evaluate whether groundwater is a major environmental transmission route for shigellosis and other enteric infections in this population.

We observed that male patient contacts were twice as likely as female contacts to develop Shigella infection during the surveillance period ( $51 \%$ vs. $27 \%$ ); all but 1 symptomatic infections in contacts were in men. The reason for this higher rate of infection among male household contacts is unknown, but a possible explanation is that men may introduce the infection into the home. Future studies should investigate the role of sex in susceptibility and transmission of Shigella infection.
Among patient households, $41 \%$ had $\geq 1$ contact who developed an initial Shigella infection after day 1 of surveillance. This finding suggests a potential opportunity to intervene in Shigella transmission in households with shigellosis patients. An intervention study that promoted handwashing with soap in Dhaka reduced the secondary infection rate for Shigella by $69 \%$ in the 10-day period after identification of the index patient compared with a control group (22). Future studies should evaluate whether this intervention would be effective in rural settings such as Mirzapur.

This study has several limitations. First, our small sample size limited our ability to detect significant differences in environmental risk factors for Shigella infection at the household level and to detect differences in behavioral risk factors at the individual level. Second, our analysis focused on pediatric index shigellosis patients, so our findings are not necessarily generalizable to older index patients. Third, we did not collect longitudinal stool samples from index patients and therefore cannot determine how long their shedding may have continued through the 1-week surveillance period. However, because all index patients received antibacterial drugs, we suspect that the shedding was minimal and that the source of Shigella infection in these households during the surveillance period was more likely from household members already infected or from a shared environmental source that we did not measure. Fourth, we used bacterial culture to detect Shigella in the stool samples. This method limited our analysis to infections with sufficiently high bacteria quantity in stool to be detected by culture. Future studies should use bacterial culture and quantitative PCR on collected stool samples. Finally, future studies should obtain $>1$ isolate from stool samples collected from each household contact to determine whether a person can shed multiple PFGE genotypes.

A main strength of our study was the environmental surveillance of household water sources, stored household water, and fly counts in study households. Second, we included households of both shigellosis patients and controls; this approach enabled us to examine rates of Shigella infection in patient households, compared with control households, and to investigate household-level risk factors for shigellosis. Third, we followed up with study households at 4 specific times during a 1-week period to obtain detailed information on potential behavioral and environmental risk factors for Shigella infection. Fourth, we used PFGE to conduct genetic characterization of strains within households.

In rural Bangladesh, household contacts of shigellosis patients are highly susceptible to Shigella infection during the week after the index patient visits a health facility for care. Our findings suggest that each shigellosis patient household represents the spread of a single infectious pathogen. Therefore, interventions for household-level risk 
factors, such as fly control, water treatment, and hygiene practices, could potentially reduce Shigella transmission in this high-risk population.

\section{Acknowledgments}

We thank all study participants and staff involved in this project. We are grateful to Mrs. Sherrilyn Fisher and Dr. Paul G. Auwaerter for their support of our study.

This work was supported by a grant from the Sherrilyn and Ken Fisher Center for Environmental Infectious Diseases at the Johns Hopkins Department of Medicine.

Dr. George is an assistant professor of International Health at the Johns Hopkins Bloomberg School of Public Health. Her research focuses on identifying environmental transmission routes for enteric infections and developing approaches for interventions in identified transmission routes of infection. She has conducted 3 cluster randomized controlled trials of safe drinking water interventions in rural and urban Bangladesh.

\section{References}

1. Lamberti LM, Bourgeois AL, Fischer Walker CL, Black RE, Sack D. Estimating diarrheal illness and deaths attributable to Shigellae and enterotoxigenic Escherichia coli among older children, adolescents, and adults in South Asia and Africa. PLoS Negl Trop Dis. 2014;8:e2705. http://dx.doi.org/10.1371/ journal.pntd.0002705

2. Kotloff KL, Winickoff JP, Ivanoff B, Clemens JD, Swerdlow DL, Sansonetti PJ, et al. Global burden of Shigella infections: implications for vaccine development and implementation of control strategies. Bull World Health Organ. 1999;77:651-66.

3. Bardhan P, Faruque AS, Naheed A, Sack DA. Decreasing shigellosis-related deaths without Shigella spp.-specific interventions, Asia. Emerg Infect Dis. 2010;16:1718-23. http://dx.doi.org/10.3201/eid1611.090934

4. von Seidlein L, Kim DR, Ali M, Lee H, Wang X, Thiem VD, et al. A multicentre study of Shigella diarrhoea in six Asian countries: disease burden, clinical manifestations, and microbiology. PLoS Med. 2006;3:e353. http://dx.doi.org/10.1371/journal.pmed.0030353

5. Kotloff KL, Nataro JP, Blackwelder WC, Nasrin D, Farag TH, Panchalingam S, et al. Burden and aetiology of diarrhoeal disease in infants and young children in developing countries (the Global Enteric Multicenter Study, GEMS): a prospective, patient-control study. Lancet. 2013;382:209-22. http://dx.doi.org/10.1016/ S0140-6736(13)60844-2

6. Das SK, Ahmed S, Ferdous F, Farzana FD, Chisti MJ, Leung DT, et al. Changing emergence of Shigella sero-groups in Bangladesh: observation from four different diarrheal disease hospitals. PLoS ONE. 2013;8:e62029. http://dx.doi.org/10.1371/journal.pone.0062029

7. Wilson R, Feldman RA, Davis J, LaVenture M. Family illness associated with Shigella infection: the interrelationship of age of the index patient and the age of household members in acquisition of illness. J Infect Dis. 1981;143:130-2. http://dx.doi.org/10.1093/ infdis/143.1.130

8. Boyce JM, Hughes JM, Alim AR, Khan M, Aziz KM, Wells JG, et al. Patterns of Shigella infection in families in rural Bangladesh. Am J Trop Med Hyg. 1982;31:1015-20.

9. Khan AI, Talukder KA, Huq S, Mondal D, Malek MA, Dutta DK, et al. Detection of intra-familial transmission of shigella infection using conventional serotyping and pulsed-field gel electrophoresis. Epidemiol Infect. 2006;134:605-11. http://dx.doi.org/10.1017/ S0950268805005534

10. Cohen D, Green M, Block C, Slepon R, Ambar R, Wasserman SS, et al. Reduction of transmission of shigellosis by control of houseflies (Musca domestica). Lancet. 1991;337:993-7. http://dx.doi.org/10.1016/0140-6736(91)92657-N

11. Levine OS, Levine MM. Houseflies (Musca domestica) as mechanical vectors of shigellosis. Rev Infect Dis. 1991;13:688-96. http://dx.doi.org/10.1093/clinids/13.4.688

12. Farag TH, Faruque AS, Wu Y, Das SK, Hossain A, Ahmed S, et al. Housefly population density correlates with shigellosis among children in Mirzapur, Bangladesh: a time series analysis. PLoS Negl Trop Dis. 2013;7:e2280. http://dx.doi.org/10.1371/journal. pntd. 0002280

13. Martin DL, Gustafson TL, Pelosi JW, Suarez L, Pierce GV. Contaminated produce - a common source for two outbreaks of Shigella gastroenteritis. Am J Epidemiol. 1986; 124:299-305.

14. Kapperud G, Rørvik LM, Hasseltvedt V, Høiby EA, Iversen BG, Staveland K, et al. Outbreak of Shigella sonnei infection traced to imported iceberg lettuce. J Clin Microbiol. 1995;33;609-14.

15. Ferguson AS, Layton AC, Mailloux BJ, Culligan PJ, Williams DE, Smartt AE, et al. Comparison of fecal indicators with pathogenic bacteria and rotavirus in groundwater. Sci Total Environ. 2012;431:314-22. http://dx.doi.org/10.1016/ j.scitotenv.2012.05.060

16. Talukder KA, Azmi IJ. Population genetics and molecular epidemiology of Shigella species. In: Faruque SM, editor. Foodborne and waterborne bacterial pathogens epidemiology, evolution and molecular biology. Norfolk (UK): Caister Academic Press; 2012. p. 63-76.

17. Ribot EM, Fair MA, Gautom R, Cameron DN, Hunter SB, Swaminathan B, et al. Standardization of pulsed-field gel electrophoresis protocols for the subtyping of Escherichia coli O157:H7, Salmonella, and Shigella for PulseNet. Foodborne Pathog Dis. 2006;3:59-67. http://dx.doi.org/10.1089/fpd.2006.3.59

18. Talukder KA, Islam MA, Dutta DK, Hassan F, Safa A, Nair GB, et al. Phenotypic and genotypic characterization of serologically atypical strains of Shigella flexneri type 4 isolated in Dhaka, Bangladesh. J Clin Microbiol. 2002;40:2490-7. http://dx.doi.org/ 10.1128/JCM.40.7.2490-2497.2002

19. Tenover FC, Arbeit RD, Goering RV, Mickelsen PA, Murray BE, Persing $\mathrm{DH}$, et al. Interpreting chromosomal DNA restriction patterns produced by pulsed-field gel electrophoresis: criteria for bacterial strain typing. J Clin Microbiol. 1995;33:2233.

20. Fernandez-Prada CM, Venkatesan MM, Franco AA, Lanata CF, Sack RB, Hartman AB, et al. Molecular epidemiology of Shigella flexneri in a diarrhoea-endemic area of Lima, Peru. Epidemiol Infect. 2004;132:303-16. http://dx.doi.org/10.1017/ S0950268803001560

21. Hughes JM, Boyce JM, Levine RJ, Khan M, Aziz KM, Huq MI, et al. Epidemiology of eltor cholera in rural Bangladesh: importance of surface water in transmission. Bull World Health Organ. 1982;60:395-404.

22. Khan MU. Interruption of shigellosis by hand washing. Trans R Soc Trop Med Hyg. 1982;76:164-8. http://dx.doi.org/ 10.1016/0035-9203(82)90266-8

Address for correspondence: Christine Marie George, Department of International Health, Program in Global Disease Epidemiology and Control, Johns Hopkins Bloomberg School of Public Health, 615 N Wolfe St, Rm E5535, Baltimore, MD 21205-2103, USA; email: cgeorg19@jhu.edu 